\title{
Correlations between the Profile of Mood States (POMS) and the WHOQOL-26 among Japanese University Students
}

\author{
Kayo Shichiri ${ }^{*}$, Masako Shibuya ${ }^{2}$, Mayumi Watanabe ${ }^{3}$, Mikie Tahashi ${ }^{1}$, Kyoko Kaminushi1, \\ Tomoko Uenoyama ${ }^{1}$, Ichiro Mashima ${ }^{1}$, Kenichi Murayama ${ }^{1}$, Takeshi Kuroda ${ }^{1}$, \\ Yoshiki Suzuki ${ }^{1}$

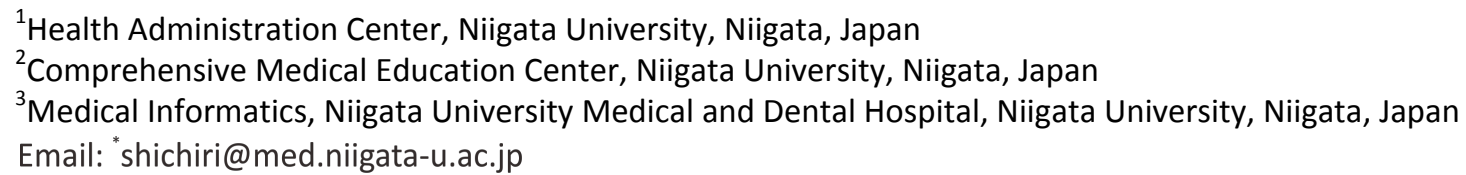

Received 2 February 2016; accepted 13 March 2016; published 16 March 2016

Copyright (C) 2016 by authors and Scientific Research Publishing Inc.

This work is licensed under the Creative Commons Attribution International License (CC BY). http://creativecommons.org/licenses/by/4.0/

(c) (i) Open Access

\begin{abstract}
In this study, we investigated six types of mood state (tension-anxiety, depression-dejection, anger-hostility, vigor, fatigue, and confusion) using the Profile of Mood States (POMS) with 40 Japanese university students. We examined five main quality of life (QOL) domains (physical health, psychological health, social relationships, and environmental health) using the World Health Organization Quality of Life Scale (WHOQOL-26). We also examined the total scale score. We examined Spearman's rank correlations between POMS mood state and QOL scores and compared male and female students' scores. The results indicated statistically significant correlations between all six mood states and three broad WHOQOL-26 domains (physical health, psychological health, and social relationships). Moreover, the relationship between mood state and QOL showed a gender difference. There were correlations between mood states and the QOL domains of social relationships and environmental health for males. In contrast, mood state correlated with the QOL domains of physical health and psychological health in females. The findings suggest that genderspecific health provision is needed to care for young university students in Japan. However, our study has several limitations; therefore, larger-scale studies with older subjects are needed in the future.
\end{abstract}

\section{Keywords}

Quality of Life (QOL), Profile of Mood States (POMS), WHOQOL-26, Correlation Analyses, Japanese University Students

\footnotetext{
${ }^{*}$ Corresponding author.
}

How to cite this paper: Shichiri, K., Shibuya, M., Watanabe, M., Tahashi, M., Kaminushi, K., Uenoyama, T., Mashima, I., Murayama, K., Kuroda, T. and Suzuki, Y. (2016) Correlations between the Profile of Mood States (POMS) and the WHOQOL26 among Japanese University Students. Health, 8, 416-420. http://dx.doi.org/10.4236/health.2016.85044 


\section{Introduction}

The quality of a person's living environment has a strong impact on their mental well-being and many researchers have reported that quality of life (QOL) can affect physical and psychological health. In this study, we investigated six types of mood state among university students in Japan using the Profile of Mood States (POMS). We also investigated five main domains of QOL using the World Health Organization Quality of Life Scale (WHOQOL-26). We examined the correlations between mood states and QOL and compared the findings for male and female students. In our previous study, we reported features of developmental level of defense mechanisms and adjustment status of university students in Japan. At that time, we revealed a sex difference in stress management and a unisex positive correlation between physical symptoms and mental symptoms [1]. If we could find such features in this study, it would be helpful for university students to live a mentally and physically healthy campus life.

\section{Methods}

\subsection{Subjects}

Participants were 40 physically and mentally healthy freshmen and sophomore students (18.9 \pm 0.5 ; 20 males and 20 females). Written informed consent was obtained from all participants and the study was approved by the institutional review board of Niigata University.

\subsection{Instruments}

\subsubsection{World Health Organization Quality of Life Scale (Japanese Version)}

The World Health Organization (WHO) defines QOL in terms of individuals' perception of their position in life in the context of the culture and value systems in which they live, and in relation to their goals, expectations, standards, and concerns. The WHO has developed two instruments to measure QOL (the WHOQOL-100 and the WHOQOL-BREF), which can be used in a variety of cultural settings. The WHOQOL-BREF (or the WHOQOL-26) is an abbreviated 26-item version of the WHOQOL-100 and was developed using data from the field trial version of the WHOQOL-100 [2]. In this study, we used the WHOQOL-26 (Japanese version), which has five broad QOL domains: physical health, psychological health, social relationships, and environmental health. A total scale score is also calculated and then analyzed [3].

\subsubsection{Profile of Mood States (Japanese Version)}

To investigate mood states, participants also completed the Profile of Mood States (POMS) [4], a self-rated scale measuring six mood states (tension-anxiety, depression-dejection, anger-hostility, vigor, fatigue, and confusion) and total mood disturbance, which is a summary score for the emotional state subscales. The POMS is a widely used, reliable measure of emotional distress [5] [6]. Research shows that the POMS is reliable for Japanese participants [7] [8]; therefore, in this study, we used the Japanese version of the POMS [9].

\subsubsection{Comparison between Male and Female}

To investigate difference between male and female students, correlations between POMS and WHOQOL-26 scores for all students $(n=40)$ were divided into two groups (males $(n=20)$ and females $(n=20))$. And then, those correlations were analyzed separately.

\subsection{Analysis of Adaptive State}

Spearman's rank method was used to investigate correlations between POMS and WHOQOL-26 scores using IBM SPSS Statistics for Windows, version 20.0 (Armonk, NY: IBM Corp.). The null hypothesis was "Students with poor QOL do not have undesirable mood states.” Statistical significance was defined as $p<0.05$ and $p<0.01$.

\section{Gender Differences in the Association between Mood State and Quality of Life}

The above-mentioned correlations (Figure 1) were examined by gender. The POMS mood state of tension-anxiety was significantly correlated only with the WHOQOL-26 social relationships domain in males $(r=-0.578)$ (Figure 2), but was significantly correlated with three WHOQOL-26 domains (physical health, psychological health, and social relationships) in females: $r=-0.826,-0.734$, and -0.666 , respectively) (Figure 3 ). 


\begin{tabular}{|c|c|c|c|c|c|c|}
\hline $\begin{array}{c}\text { POMS } \\
\text { WHOQOL-26 }\end{array}$ & $\begin{array}{l}\text { Tension- } \\
\text { Anxiety }\end{array}$ & $\begin{array}{c}\text { Depression- } \\
\text { Dejection }\end{array}$ & $\begin{array}{c}\text { Anger- } \\
\text { Hostility }\end{array}$ & Vigor & Fatigue & Confusion \\
\hline \multirow{2}{*}{ Physical health } & $* *$ & $* *$ & $* *$ & * & * & ** \\
\hline & -0.469 & -0.563 & -0.423 & 0.314 & -0.393 & -0.574 \\
\hline \multirow{2}{*}{ Psychological } & ** & ** & ** & ** & ** & $* *$ \\
\hline & -0.439 & -0.593 & -0.407 & 0.520 & -0.439 & -0.555 \\
\hline \multirow{2}{*}{ Social relationships } & ** & $* *$ & ** & * & ** & ** \\
\hline & -0.676 & -0.624 & -0.436 & 0.398 & -0.566 & -0.538 \\
\hline Environment & - & $\begin{array}{c}* * \\
-0.325\end{array}$ & - & - & $\begin{array}{c}* * \\
-0.445\end{array}$ & $\begin{array}{c}* * \\
-0.441\end{array}$ \\
\hline Total & $\stackrel{*}{*}$ & $\begin{array}{c}* * \\
-0.483\end{array}$ & $\stackrel{*}{*}$ & - & - & $\begin{array}{c}* * \\
-0.458\end{array}$ \\
\hline (average) & $\begin{array}{c}* * \\
-0.604\end{array}$ & $\begin{array}{c}* * \\
-0.690\end{array}$ & $\begin{array}{c}* * \\
-0.480\end{array}$ & $\begin{array}{c}* * \\
0.504\end{array}$ & $\begin{array}{c}* * \\
-0.577\end{array}$ & $\begin{array}{c}* * \\
-0.713\end{array}$ \\
\hline
\end{tabular}

Figure 1. Correlations between POMS and WHOQOL-26 scores for all students $(n=40 ; 20$ males, 20 females). Figures are values of Spearman's $r ;{ }^{*} p<0.05$ and ${ }^{* *} p<0.01$.

\begin{tabular}{|c|c|c|c|c|c|c|}
\hline $\begin{array}{c}\text { POMS } \\
\text { WHOQOL-26 }\end{array}$ & $\begin{array}{l}\text { Tension- } \\
\text { Anxiety }\end{array}$ & $\begin{array}{c}\text { Depression- } \\
\text { Dejection }\end{array}$ & $\begin{array}{c}\text { Anger- } \\
\text { Hostility }\end{array}$ & Vigor & Fatigue & Confusion \\
\hline Physical health & - & $\begin{array}{c}* \\
-0.517\end{array}$ & - & - & - & $\begin{array}{c}* * \\
-0.616\end{array}$ \\
\hline Psychological & - & - & - & $\begin{array}{c}* * \\
0.598\end{array}$ & $\begin{array}{c}* * \\
-0.608\end{array}$ & $\stackrel{*}{*}$ \\
\hline Social relationships & $\begin{array}{c}* * \\
-0.578\end{array}$ & $\stackrel{*}{*}$ & - & - & $\begin{array}{c}* * \\
-0.761\end{array}$ & $\begin{array}{c}* \\
-0.512\end{array}$ \\
\hline Environment & - & $\begin{array}{c}* \\
-0.535\end{array}$ & $\begin{array}{c}* \\
-0.495\end{array}$ & - & $\begin{array}{c}* * \\
-0.784\end{array}$ & $\begin{array}{c}* * \\
-0.642\end{array}$ \\
\hline Total & - & $\stackrel{*}{*}$ & - & - & - & $\stackrel{*}{*}$ \\
\hline (average) & $\begin{array}{c}* \\
-0.479\end{array}$ & $\begin{array}{c}* * \\
-0.631\end{array}$ & - & $\begin{array}{c}* \\
0.531\end{array}$ & $\begin{array}{c}* * \\
-0.774\end{array}$ & $\begin{array}{c}* * \\
-0.744\end{array}$ \\
\hline
\end{tabular}

Figure 2. Correlations between POMS and WHOQOL-26 scores for male students $(\mathrm{n}=20)$. Figures are values of Spearman's $r$; $p<0.05$ and ${ }^{* *} p<0.01$.

\begin{tabular}{ccccccc}
\hline $\begin{array}{c}\text { POMS } \\
\text { WHOQOL-26 }\end{array}$ & $\begin{array}{c}\text { Tension- } \\
\text { Anxiety }\end{array}$ & $\begin{array}{c}\text { Depression- } \\
\text { Dejection }\end{array}$ & $\begin{array}{c}\text { Anger- } \\
\text { Hostility }\end{array}$ & Vigor & Fatigue & Confusion \\
\hline Physical health & $* *$ & $* *$ & $* *$ & - & $*$ & $* *$ \\
& -0.826 & -0.718 & -0.644 & $*$ & -0.548 & -0.565 \\
Psychological & $* *$ & $* *$ & $* *$ & $*$ & $*$ & $* *$ \\
Social relationships & -0.734 & -0.881 & -0.627 & 0.447 & -0.499 & -0.704 \\
Environment & -0.666 & -0.621 & - & $*$ & - & - \\
Total & - & - & - & - & - & - \\
(average) & - & - & $* *$ & & - & - \\
\hline
\end{tabular}

Figure 3. Correlations between POMS and WHOQOL-26 scores for female students $(n=20)$. Figures are values of Spearman's $r{ }^{*} p<0.05$ and ${ }^{* *} p<0.01$.

The POMS mood state of anger-hostility was significantly correlated with only the WHOQOL-26 domain of environmental health in males $(r=-0.495)$ (Figure 2$)$, but was significantly correlated with the WHOQOL-26 domains of physical health and psychological health in females ( $r=-0.644,-0.627$, respectively) (Figure 3).

Therefore, the results indicated that mood state correlated with the QOL domains of social relationships and environmental health for males (Figure 2). In contrast, mood state correlated with the QOL domains of physical health and psychological health for females (Figure 3). Thus, the relationship between mood state and QOL showed a gender difference. 


\section{Discussion}

Our results rejected the null hypothesis, "Students with poor QOL do not have undesirable mood states", and supported the alternative hypothesis: "Students with poor QOL have undesirable mood states”. In fact, there was a significant correlation between POMS and WHOQOL-26 scores.

Moreover, the results indicated a gender difference. Many students suffer from mood disorders and visit the Health Administration Center, which helps students to lead mentally and physically healthy lives on campus. For example, several female students have presented with premenstrual dysphoric disorder (PMDD). Therefore, the physical as well as the psychological health of females needs to be considered, as indicated by the present findings. In contrast, mood states in male students were correlated more with social relationships and environmental health.

Earlier reports by the American psychiatrist Walters [10], and by Kasahara in Japan [11], identified the existence of an increasing number of apathetic students, who withdrew from both academic activities and from society in general. However, the Lehman Brothers crash that triggered the 2008 financial crisis changed the way that students think; students today are more vividly aware of the importance of finding employment.

About $80 \%$ of male and female graduates find permanent employment. Male graduates maintain this status from their 20s to their 50s [12]. However, $10 \%$ of female graduates give up their careers in their 30s and less than $60 \%$ of them retain full-time employment in their 40 s. It may be considered that they are more likely to give up their careers to raise children.

These facts may help to explain the gender differences in our results. It is possible that female students are not able to be as career-minded as male students. In other words, it may be that male students become aware of today's aggressively competitive society earlier than female students.

Our study has several limitations. First, we had a limited number of participants; therefore, further research (e.g., larger-scale studies) is required to support these findings. Second, our participants were aged about 20 years old, so more work on older participants is needed. During four year campus life, student may change in their personality and career choice before going out into the world. Therefore, the same investigation is necessary in senior university students and these correlations are needed to be compared with our results of younger students. These would be valuable factors to assess in any future study.

\section{Conclusion}

We found strong correlations between POMS scores and WHOQOL-26 scores for the three main QOL domains of physical health, psychological health, and social relationships. For female students, the association with mood state was strongest for physical health. For male students, the association with mood state was strongest for social relationships. Therefore, the findings indicated that gender-specific health provision was important to maintain positive and stable mood states in students.

\section{Acknowledgements}

The authors thank all the student volunteers who participated in this study.

\section{References}

[1] Shichiri, K., Shibuya, M., Murayama, K., Sato, C., Kaminushi, K., Uenoyama, T., Mashima, I., Kuroda, T. and Suzuki, Y. (2015) Features of Developmental Level of Defense Mechanisms and Adjustment Status of University Students in Japan. Health, 7, 52-57.

[2] Division of Mental Health and Prevention of Substance Abuse, World Health Organization (1997) Measuring Quality of Life. The World Health Organization Quality of Life Instruments The WHOQOL-100 and the WHOQOL-BREF. http://www.who.int/mental_health/media/68.pdf

[3] Tasaki, M. and Nakane, Y. (1997) Companion to WHO/QHL-26: Division of Mental Health and Protection of Substance Abuse. 1st Edition, Kaneko Shobo Ltd., Tokyo.

[4] McNair, D., Lorr, A. and Droppleman, L. (1971) EITS Manual for the Profile of Mood States. Educational and Industrial Testing Service, San Diego.

[5] McCorkle, R. and Quint-Benoliel, J. (1983) Symptom Distress, Current Concerns and Mood Disturbance after Diagnosis of Life-Threatening Disease. Social Science \& Medicine, 17, 431-438. 
http://www.ncbi.nlm.nih.gov/pubmed/?term=McCorkle+R\%2C+Quint-Benoliel+J http://dx.doi.org/10.1016/0277-9536(83)90348-9

[6] Silberfarb, P.M., Holland, J.C.B., Anbar, D., Balma, G., Maurer, H., Chahinian, A.P. and Comis, R. (1983) Psychological Response of Patients Receiving Two Drug Regimens for Lung Carcinoma. American Journal of Psychiatry, 140, 110-111. http://dx.doi.org/10.1176/ajp.140.1.110

[7] Akechi, T., Fukue-Saeki, M., Kugaya, A. and Okamura, H. (2000) Psychometric Properties of the Japanese Version of the Mental Adjustment to Cancer (MAC) Scale. Psycho-Oncology, 9, 395-401.

http://www.ncbi.nlm.nih.gov/pubmed/11038477 http://dx.doi.org/10.1002/1099-1611(200009/10)9:5<395::AID-PON472>3.0.CO;2-O

[8] Yokoyama, K., Araki, S., Kawakami, N. and Takeshita, T. (1990) Production of Japanese Edition of Profile of Mood States (POMS): Assessment of Reliability and Validity. Japanese Journal of Public Health, 37, 913-918.

[9] Yokoyama, K. and Araki, S. (2000) Companion to POMS. 3rd Edition, Kaneko Shobo Ltd., Tokyo.

[10] Walters, P.A. (1971) Student Apathy, Emotional Problems of the Student. 2nd Edition, Appleton-Century-Crofts Ltd, New York, 129-147.

[11] Tsuchikawa, T. (1981) Student Apathy. In: Kasahara, Y. and Yamada, K., Eds., Campus Syndrome, 1st Edition, Kobundo Ltd., Tokyo, 143-166.

[12] Japanese Ministry of Health, Labour and Welfare (2009) Daisotsu-Josei no hataraki-kata Hataraku-Josei no Jitsujo(Japanese). The Way Female Graduates Work the Current Condition of Career Woman. Japanese Ministry of Health, Labour and Welfare. www.mhlw.go.jp/houdou/2009/03/dl/h0326-1d.pdf 